\title{
Assessment of Prevalence of Diabetic Retinopathy in Western Madhya Pradesh
}

\author{
Authors \\ Sadhana Sewak ${ }^{1}$, Yadvendra Singh Solanki ${ }^{2}$, Chandrasheela Gupta ${ }^{3}$ \\ ${ }^{1}$ Assistant Professor, Department of Zoology, SRJ Government Girls' College, Neemuch (MP) INDIA \\ ${ }^{2}$ Assistant Professor, Department of Zoology, Swami Vivekanand Government PG College, Neemuch (MP) \\ INDIA \\ ${ }^{3}$ Professor, Head, Zoology Department, Rajiv Gandhi Government PG College, Mandsaur (MP) INDIA \\ Corresponding Author \\ Sadhana Sewak \\ Email: sadhanasewak@gmail.com
}

\begin{abstract}
Background and Aim: Diabetic Retinopathy is the dreadful micro vascular complication of diabetes which leads to blindness or loss of eye. It has become the major health problem worldwide. However, this morbidity is largely preventable and treatable. Despite new treating therapies and management strategies, there is no curb on the progression and development of this disease. This study was aimed to assess the prevalence of diabetic retinopathy among the diabetic patients visited in the Gomabai Eye Hospital in the Neemuch District, Madhya Pradesh.

Methodology: 446 selected patients were included. At the time of screening, informed consent was taken and age, gender and duration of diabetes was noted in designed questionnaire. Patients were evaluated for Diabetic retinopathy by Fundus examination. Findings were recorded and retinopathy was classified according to ETDRS Classification

Results: In the present study, prevalence of Diabetic retinopathy was found $28.4 \%$. Out of 446 patients, 232 were males and 214 were females. $69.06 \%$ patients were found affected with NPDR and $18.60 \%$ with PDR. Significant association was found between age, duration and diabetic retinopathy.

Conclusion: Regular screening and awareness camps to detect diabetic retinopathy at early stage are necessary to understand the associated risk factors, so that proper management and treatment can be extended to the affected to prevent most of the diabetes related blindness.

Keywords: Micro vascular, Morbidity, Retinopathy, Diabetes.
\end{abstract}

\section{Introduction}

Diabetes is a metabolic disease which is characterised by hyperglycaemia and glycosuria which occurs due to either the scarcity of insulin or presence of insulin resistance. The pathogenesis for type 2 diabetes is still not diagnosed. The different factors which can be considered to play its role in pathogenesis are genetics, age, duration, gestation, environmental factors etc. Diabetic retinopathy is a well-recognized micro vascular long term complication of diabetes mellitus. Visual disability from diabetic retinopathy is a 
significant public health problem. It is found to be one of the major reasons for loss of vision among young diabetic patients as studies suggests it as the 5th most common case leading to impaired vision and blindness. This disease usually doesn't have any early signs and symptoms. Studies from literature suggests that a grave situation of diabetes and its complications in the Indian scenario. The work by Mohan, et al (2007) suggests that the global outbreak of the disease has shown an alarming rise with an extremely serious situation in India. As per the International Diabetes Foundation in 2015, almost 145 million people were suffering from diabetes and predicted an estimated increase of diabetic individuals approximately to 642 million by 2040, rightly referring to the country a diabetic capital of the world. The reason of this has been deduced as the phenotypic characteristics of the Asian-Indian population comprising of increased resistance to insulin, high levels of C-reactive protein and high waist to hip ratio. Hence, appropriate interventions are required in terms of risk assessment, lifestyle changes as well as drug therapy to either reduce its incidence or delay its complications.

Prevalence of DR in India varies from study to study. A systemic review was conducted by Yau et al in 2012 on 35 studies, $34.7 \%$ individuals were found to have diabetic retinopathy with increased incidences with increase in duration of diabetes, blood pressure levels and increased haemoglobin A1c levels. The UKPDS (UK Prospective Diabetes Study) showed that intensive glucose control reduced the risk of a $23.5 \%$, mild retinopathy constituting $11.3 \%$, moderate, severe retinopathy $11.08 \%$ and proliferative retinopathy $1.12 \%$. Insulin treatment, duration of diabetes, age at examination, HbA1c, systolic blood pressure, cholesterol, triglyceride and micro albumin were found to be related to the development and the progression of retinopathy.

The situation in India is equally severe and as per the studies, as high as 6 million diabetics have been found to be associated with risks of visual impairment. A nationwide analysis of this condition is still deficient but analysis of the literature suggests that around 20-25\% diabetics in India suffer from this grave condition. Few studies like ICMR studies and national urban diabetes survey was conducted to estimate the data of prevalence of diabetic retinopathy in India. A comprehensive study had been carried out to assess the prevalence of diabetic retinopathy. amongst patients suffering from diabetes in the Vindhya region (Singh, et al 2012), showed 12\% individuals affected by pre-proliferative changes while $2 \%$ individuals included in the study had complete blindness owing to the condition. Rema and Pradeepa (2007) found 17.6\% individuals of urban areas of Chennai having diabetic retinopathy. The study of Dandona (1999) in diabetic retinopathy explains about the need of a nationwide case study on diabetes and its complications in the country in both rural and urban setting.

In a population based cross sectional study done by Raman et. al, (2009) to know the prevalence of diabetic retinopathy in Chennai, India found $18 \%$ incidence of diabetic retinopathy. Duration of diabetes was analyzed as the major risk factor associated with the diabetic retinopathy including age and gender association with increased risk of diabetes. Rani et, al. (2009) estimated the prevalence of diabetic retinopathy in rural population of Tamil Nadu. On examination, an overall of $17.6 \%$ patients of diabetic retinopathy, $5.6 \%$ patients were under higher stage of diabetic retinopathy having strong association of the disease with duration of diabetes, lean body mass index, and age and increased systolic blood pressure. Sachdeva, et al (2010) in North Indian people studied Leakage of lipoproteins, an important causative factor for formation of hard exudates which leads to macular oedema, an important reason for loss of eyesight leading to blindness. Checking of systemic manifestations and conditions like blood pressure, haemoglobin, HbA1c or glycated haemoglobin, LDL etc. were considered as an important part of the study. 
Purushottam Giri et al (2012) recorded $44.4 \%$ Diabetic retinopathy in Loni, Maharashtra.

There is paucity in the literature regarding the prevalence of DR in central India. The aim of the study was to evaluate the prevalence of retinopathy and its relation with various risk factors in Type 2 diabetic patients in the Neemuch district located in the western part of Madhya Pradesh.

\section{Material and Methods}

A study was performed on randomly selected diabetic patients of Gomabai Netralaya, Neemuch. 1570 patients were found diabetic during study period. 446 patients confirmed with type 2 diabetes were examined for symptoms of retinopathy. The study was undertaken for less than minimal risk involved as per ICMR Guidelines and recommendation of Ethical Committee of the institute. Informed consent was taken while completing the screening form. Patients of both sexes of different age groups were selected. Diagnosis of blood sugar was done using recommendations of ADA (American Diabetic Foundation), Demographic data such as age, gender, duration of diabetes, history of hypertension was entered in questionnaire. Retinal examination was done with Direct and Indirect Ophthalmoscope. Fundus examination was performed for screening of diabetic retinopathy and cases were classified according to the stages of diabetic retinopathy. Data were analysed statistically. Percentages and proportions were calculated wherever appropriate. Duration of DM was defined as the time period between the time of diagnosis and the time of examination. They were categorized into the following groups: Group 1 as $<5$ years, Group 2 as 5-10 years, Group 3 as above 10 years. For clinical findings Retinopathy was classified according to (DRS) Diabetic Retinopathy Study and (ETDRS) Early Treatment Diabetic Retinopathy Study.

\section{Results}

The prevalence of retinopathy is $28.4 \%$ in examined diabetic patients. Of the 446 patients who had signs of diabetic retinopathy, 232 $(52.02 \%)$ were males and $214(47.98 \%)$ were females. 55 (12.33\%) showed no retinal damage, Whereas $308(69.06 \%)$ patients were found to be affected with Non Proliferative Diabetic Retinopathy, 83 (18.60\%) showed Sight threatening proliferative changes. There is significant progression of retinopathy with the longer duration of diabetes. Duration of diabetes, age at examination was found to be significantly correlated to the development and the progression of retinopathy.

Table 1 shows distribution of diabetic patients according to retinopathy. Increase in prevalence of diabetic retinopathy was seen with increase in age. Table 2 shows gender-wise distribution for prevalence of diabetic retinopathy. Table- 3 shows distribution of patients with DR by age.

Table 1- Distribution of sample according to grading of retinopathy

\begin{tabular}{|c|c|c|c|}
\hline $\mathrm{N}=446$ & $\mathrm{~N}=55$ & $\mathrm{~N}=308$ & $\mathrm{~N}=83$ \\
\hline $\begin{array}{l}\text { Total no. of } \\
\text { patients } \\
\text { (in \%) }\end{array}$ & $\begin{array}{c}\text { Patients } \\
\text { with No DR } \\
\text { (in\%) }\end{array}$ & $\begin{array}{c}\text { Patients } \\
\text { with NPDR } \\
\text { (in\%) }\end{array}$ & $\begin{array}{c}\text { Patients } \\
\text { with PDR } \\
\text { (in\%) }\end{array}$ \\
\hline 28.4 & 12.33 & 69.06 & 18.60 \\
\hline
\end{tabular}

Table 2- Distribution of Diabetic retinopathy by gender

\begin{tabular}{|l|c|c|c|c|}
\hline \multirow{3}{*}{ Gender } & $\mathrm{N}=446$ & $\mathrm{~N}=55$ & $\mathrm{~N}=308$ & $\mathrm{~N}=83$ \\
\cline { 2 - 5 } & $\begin{array}{c}\text { No of patients } \\
\text { (in \%) }\end{array}$ & $\begin{array}{c}\text { No DR } \\
\text { (in\%) }\end{array}$ & $\begin{array}{c}\text { NPDR } \\
\text { (in\%) }\end{array}$ & $\begin{array}{c}\text { PDR } \\
\text { (in\%) }\end{array}$ \\
\hline Male & $\begin{array}{c}232 \\
(52.02)\end{array}$ & $\begin{array}{c}27 \\
(49.09)\end{array}$ & $\begin{array}{c}165 \\
(53.57)\end{array}$ & $40(48.19)$ \\
\hline Female & $\begin{array}{c}214 \\
(47.98)\end{array}$ & $\begin{array}{c}28 \\
(50.91)\end{array}$ & $\begin{array}{c}143 \\
(46.43)\end{array}$ & $43(51.81)$ \\
\hline
\end{tabular}

Table 3- Distribution of patients with DR by age

\begin{tabular}{|c|c|c|c|c|}
\hline & $\mathrm{N}=170$ & $\mathrm{~N}=17$ & $\mathrm{~N}=116$ & $\mathrm{~N}=37$ \\
\hline Age Group & $\begin{array}{c}\text { No of } \\
\text { patients (in } \\
\%)\end{array}$ & $\begin{array}{l}\text { No DR } \\
\text { (in } \% \text { ) }\end{array}$ & $\begin{array}{l}\text { NPDR } \\
\text { (in \%) }\end{array}$ & $\begin{array}{c}\text { PDR } \\
\text { (in \%) }\end{array}$ \\
\hline Below 40 & $18(4.04)$ & $\begin{array}{c}13 \\
(72.22)\end{array}$ & $\begin{array}{c}5 \\
(27.78)\end{array}$ & $0(0)$ \\
\hline $40-60$ & $258(57.85)$ & $\begin{array}{c}25 \\
(9.69)\end{array}$ & $\begin{array}{c}187 \\
(72.48)\end{array}$ & $\begin{array}{c}46 \\
(17.83) \\
\end{array}$ \\
\hline Above 60 & $170(38.12)$ & $17(10)$ & $\begin{array}{c}116 \\
(68.24)\end{array}$ & $\begin{array}{c}37 \\
(21.76)\end{array}$ \\
\hline
\end{tabular}



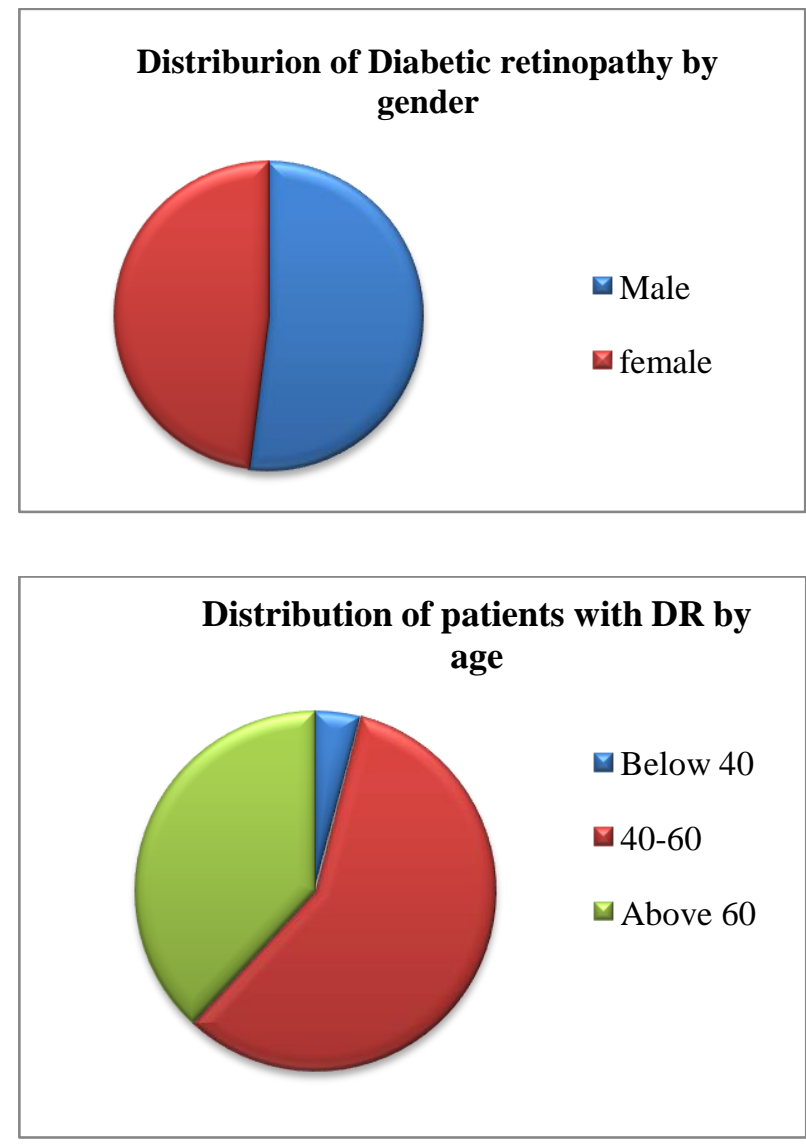

\section{Discussion}

In our study the prevalence of diabetic retinopathy was $28.4 \%$. This was found similar and close with the findings of Narendran et al (26.2\%), Agrawal et al (28.9\%), of Kashmir study (27\%). It is higher as compared to the diabetes population in South India as reported by Rani et al (17.6\%), APDES study (22.4\%), Chennai Urban Rural Epidemiological Study (CURES) 20.8\%.

In the present study, majority $69.06 \%$ patients with diabetic retinopathy had NPDR (Non Proliferative Diabetic Retinopathy), and $18.60 \%$ patients had PDR. These results are closer with the findings in the various Indian studies. Similar study conducted by Aggarwal et al. showed 79.8\% patients with NPDR, $14.6 \%$ patients with PDR, and $5.8 \%$ patients had maculopathy. The prevalence of DR increases with increasing age group as in other studies. In our study, prevalence is much higher in the 40-60 years age group. This observation suggests that DR is an age related condition. This was similar to the results of the studies of Namperumalsamy (2010), Sachdeva et al, Koushiki, Mani (2017). In a study conducted by Raman et al and Reema and Pradeepa, they examined that longer duration of diabetes has greater risk of diabetic retinopathy; we also found significant progression of Diabetic retinopathy with increased duration. The comparison between male and female did not show any significant difference with combined total analysis. However a small female predisposition is seen. This result differs from the studies done in other parts of India. Which was higher in men than in women?

\section{Conclusion}

Diabetic retinopathy is governed by age, duration of diabetes and systemic as well as other ocular factors. Unawareness, scarcity of improved health services, illiteracy in rural areas and changing life styles, lack of awareness of risk factors responsible for diabetes in urban areas is the cause of sight threatening morbidities. The influencing factors can be controlled by therapies and changes in life style. Proper management and timely intervention for regular screening to detect diabetic retinopathy is highly recommended as early detection and timely treatment can delay or prevent most of the diabetes-related blindness. Further studies in this area are needed to access risk factors to prevent the vision complications and improve the life quality.

\section{References}

1. Dandona, L Dandona, R., Naduvilath, T.J., McCarty, C.A. and Rao, G.N., 1999. Population based assessment of diabetic retinopathy in an urban population in southern India. British Journal of Ophthalmology, 83(8), pp.937-940.

2. Narendran V., John, R.K., Raghuram, A., Ravindran, R.D., Nirmalan, P.K. and Thulasiraj, R.D., 2002. Diabetic retinopathy among self reported diabetics in southern India: a population based assessment. British Journal of Ophthalmology, 86(9), pp.1014-1018.

3. Rema, M., Deepa, R. and Mohan, V., 2000. Prevalence of retinopathy at 
diagnosis among type 2 diabeetic patients attending a diabetic centre in South India. British Journal of Opthalmology. 84(9), pp 1058-1060.

4. Raman, R., Rani, P.K., Rachepalle, S.R., Gnanamoorthy, P., Uthra, S., Kumaramanickavel, G. and Sharma, T., 2009. Prevalence of diabetic retinopathy in India: Sankara Nethralaya diabetic retinopathy epidemiology and molecular genetics study report 2. Ophthalmo-logy, 116(2), pp.311-318.

5. Yau J, W. Rogers, S.L. Kawasaki R, Lamoureux, E L Kowalski, J W., Bek T., Chen S J., Dekker, J M Flecher A, Grauslund J and Haffner S,.2012. Global prevalence and major risk factors of diabetic retinopathy. Diabetes Care, 35(3), pp 554-556.

6. Rema, M. and Pradeepa, R., 2007. Diabetic retinopathy: an Indian perspective. Indian journal of medical research, 125(3), p.297.

7. Pradeepa, R., Anitha, B., Mohan, V., Ganesan, A. and Rema, M., 2008. Risk factors for diabetic retinopathy in a South Indian type 2 diabetic population-the Chennai Urban Rural Epidemiology Study (CURES) Eye Study 4. Diabetic Medicine, 25(5), pp.536-542.

8. Agarwal, S., Raman, R., Paul, P.G., Rani, P.K., Uthra, S., Gayathree, R., McCarty, C., Kumaramanickavel, G. and Sharma, T., 2005. Sankara Nethralaya-Diabetic Retinopathy Epidemiology and Molecular Genetic Study (SN_DREAMS 1): Study Design and Research Methodology. Ophthalmic epidemiology, 12(2), pp.143153.

9. Rani, P.K., Raman, R., Chandrakantan, A., Pal, S.S., Perumal, G.M. and Sharma, T., 2009. Risk factors for diabetic retinopathy in self-reported rural population with diabetes. Journal of postgraduate medicine, 55(2), p.92.
10. Ramasamy, K., Raman, R. and Tandon, M., 2013. Current state of care for diabetic retinopathy in India. Current diabetes reports, 13(4), pp.460-468.

11. Mohan, V., Sandeep, S., Deepa, R., Shah, B., \& Varghese, C. (2007). Epidemiology of type 2 diabetes: Indian scenario. Indian Journal of medical Research, 125(3), 217.

12. Ramachandran, A., \& Snehalatha, C. (2009). Current scenario of diabetes in India. Journal of diabetes, 1(1), 18-28.

13. Raman, R., Bhojwani, D. N., \& Sharma, T. (2014). How accurate is the diagnosis of diabetic retinopathy on telescreening? The Indian scenario. Rural Remote Health, 14, 2809.

14. Jindal, S., Gupta, S., Gupta, R., Kakkar, A., Singh, H. V., Gupta, K., \& Singh, S. (2011). Platelet indices in diabetes mellitus: indicators of diabetic microvascular complications. Hematology, 16(2), 86-89.

15. Gupta, N., \& Gupta, R. Diabetic Retinopathy-An Update.

16. Singh P., Wadhwani, E., Gupta R., Agrawal R. C., Maheshwari S. K (2012). Prevalence of Diabetic Retinopathy in Diabetic Patients of Vindhya Region,2 (4), 1-3 available (online) at http://www.ijsrp.org/research_paper_apr20 12/ijsrp-apr-2012-21.pdf last assessed on 24/6/17.

17. Sachdev, N., \& Sahni, A. (2010). Association of systemic risk factors with the severity of retinal hard exudates in a north Indian population.

18. Sripriya, S., Raman, R., Soumittra, N., \& Pandian, A. J. (2017). Current Research Perspectives in Understanding Diabetic Retinopathy. In Advances in Vision Research, Volume I (pp. 259-274). Springer Japan. 